\title{
Comparative Analysis of Marketing Efficiencies of Paddy and Locally Milled Rice (Oryza sativaL.) Marketers in the Federal Capital Territory, Nigeria
}

\author{
E. A. Aiyedun, E. S. Ebukiba, M. A. Otitoju, E. O. Ogbole, and A. Luka
}

\section{ABSTRACT}

\begin{abstract}
The study conducted a comparative analysis of the marketing efficiencies of paddy and locally milled rice marketers in the Federal Capital Territory, Nigeria. It specifically examined the marketing efficiencies and factors influencing marketing efficiencies of paddy and locally milled rice marketers in the study area. Primary data were collected using wellstructured pre-tested questionnaires while a multistage sampling technique was adopted to obtain responses from respondents. Descriptive (mean, frequency and percentages) and inferential statistics (shepherd's index and multiple regression analysis) were used to analyze the data. In using shepherd's index, the results revealed $78 \%$ and $77 \%$ marketing efficiencies for paddy and locally milled rice respectively while the multiple regression analysis revealed sex, household size, availability of storage facility and contract marketing arrangement were significant to marketing efficiency of paddy rice; while membership of a market association, cost of purchasing rice, selling price of rice, availability of storage facility and contract arrangement were significant to marketing efficiency of locally milled rice. The study concludes that paddy rice marketers are more efficient in the study area and therefore recommends the initiation of more contract arrangements between investors and marketers in the area, while marketers should be encouraged to join marketing associations to take advantage of the endless benefits to be gained. It also recommends the formulation of policies that favour inclusivity of youths and women in the trade.
\end{abstract}

Keywords: Comparative Analysis, Marketing, Milled Rice, Paddy.
Submitted : June 16, 2021

Published : November 06, 2021

ISSN: $2684-1827$

DOI: $10.24018 /$ ejfood.2021.3.6.324

\section{E. A. Aiydedu}

Department of Agricultural Economics, University of Abuja, Nigeria.

E. S. Ebukiba

Department of Agricultural Economic, University of Abuja, Nigeria.

(e-mail: odudu4sure@gmail.com)

M. A. Otitoju

Department of Agricultural Economics, University of Abuja, Nigeria.

(e-mail: maotitoju@ gmail.com)

E. O. Ogbole*

Department of Agricultural Economics, University of Abuja, Nigeria.

(e-mail: esther_ogbole@yahoo.com)

A. Luka

Department of Agricultural Economics, University of Abuja, Nigeria.

(e-mail: gqluka11@gmail.com)

*Corresponding Author

\section{INTRODUCTION}

Rice is a staple food consumed in many Nigerian homes often in different forms (fermented, boiled or ground). It is the most commonly consumed cereal grain in different parts of the world especially Asia which accounts for $90 \%$ of rice produced and consumed annually [1], [2] reports that rice is a crop of global importance as it is widely consumed by a number of households, adding that rice is primarily known as high energy, high calorie food ( 345 calories per $100 \mathrm{~g}$ ) with high biological value of proteins, phosphorus, iron, some amount of Calcium, and Vitamin B in small quantities. Rice is also low in fats, salt, and cholesterol, [3], and contains minerals such as Iron (Fe), Zinc ( $\mathrm{Zn})$ [4]; Manganese (Mn), and Copper $(\mathrm{Cu})$ in trace amounts, essential amino acids like histicdine, methionine, tryptophan, and cysteine.

As of 2017, Nigeria was the second largest producer of rice in West Africa [5], producing 3.7million tones of milled rice annually behind Egypt. This accounted for a short fall as 6.4 million tonnes of rice were consumed per annum, which explained why Nigeria was the third largest importer of rice in the world. A March 2019 publication by the Africa Rice Centre explained that due to policy changes by the Egyptian government in favour of managing water resources, Nigeria overtook Egypt to become the largest producer of rice after production increased to about 4 million tonnes of milled rice per annum. This affirms that Nigeria has the potential to be self-sufficient in rice production, both for food, industrial raw materials, and exports [6]. Unfortunately, despite the country's potentials and suitable agro-ecologies (upland, rain-fed lowland, irrigated lowland, deep water and mangrove swamp) that favour the achievement of self-sufficiency in rice production [7], [8], rice is currently cultivated commercially in only about 11 States, with small-holder farmers accounting for $80 \%$ of the country's annual harvest. These States are Ebonyi, Kaduna, Niger, Kano, Lagos, Kebbi, Cross-River, Enugu, Taraba, Borno, Benue [5]. The potential for self-sufficiency in rice production makes the crop a potential contributor to domestic food security and foreign exchange earnings [9].

Rice consumption in the country continues to increase rapidly due to a shift in consumer preference and urbanization among other factors [10]. The ban on foreign rice importation by the Mohammadu Buhari led administration has also increased consumer preference for local rice [11] making it imperative to intensify domestic production and strengthen local marketing systems to cater to increasing demands. 
Although it also aggravated the activities of rice smugglers along the country's land borders [12], thus, saturating Nigerian markets with foreign polished rice at the time.

Rice marketing in Nigeria is mainly characterized by a weak marketing system arising from poor infrastructural development, huge government taxes, importation, price fluctuations, unstable income, inadequate storage facilities, inefficient pricing of the commodity, poor grain quality, inability to access credit, lack of industrial drive and low profit margins owing to inefficient pricing as well as low competitiveness [13]-[16]. In addition to the aforementioned challenges, this aspect of the commodity value chain has little or no institutional backing. The Anchor Borrowers Programme which is an initiative of the Muhammadu Buhari led administration created to foster partnerships between farmers, financial and other anchor institutions such that a farmer has the market for his produce even before harvest, is yet to achieve the desired result in the rice value-chain, although the Programme has contributed to linking about 120,000 rice farmers with millers and industrial off-takers. Also worthy of note are efforts by internationally funded programmes and projects such as Propcom Maikarfi - a UK government funded programme focused on facilitating relationships between players in the agricultural and rural markets, and the USAID funded MARKETS II Project working with the Nigerian government and the private sector to identify and alleviate constraints to well-functioning markets for agricultural products including rice.

Owing to the backdrop of these challenges and incommensurate efforts to fast track improvements, it has therefore become imperative to investigate the level of efficiency or inefficiency as well as challenges peculiar to marketing paddy and locally milled rice in the Federal Capital Territory such that recommendations are made to expose and build on gaps in the study area. The specific objectives of the research are to:

i) Determine the marketing efficiencies of paddy and locally milled rice in the FCT; and

ii) Evaluate factors determining marketing efficiencies of paddy and locally milled rice in the FCT.

$\mathrm{Ho}_{1}$ : There is no significant difference between the marketing efficiencies of paddy and locally milled rice in the FCT.

\section{LITERATURE REVIEW}

\section{A. Marketing System}

According to [17], a marketing system includes marketing chains, price, products to be marketed and consumers' utility. A marketing system refers to the entire framework from production to distribution and all the actors involved. [18] as cited by [19] stated that an efficient marketing system is expected to provide processing, storage, and transportation functions from the producer to the final consumer and sufficient information from the consumer through to the producer in form of feedback for improvements. The study also added that in as much as an efficient marketing system plays a major role in the developmental process, it is dependent on efficient allocation and use of resources.

\section{B. Marketing Analysis}

Market analysis involves the evaluation of the commercial market in which a business operates. It is also an assessment of the growth and profit opportunities open to a commodity within a market. Market analysis involves profitability determination, a study of competitors, marketing channels, market trends, cost structure, growth driver as well as a clear understanding of the attractiveness, evolving opportunities and threats within a market [20].

\section{Marketing Efficiency}

Marketing efficiency is measured by market performance affected by market structure and conduct. It refers to the provision of goods and services to consumers at the least cost possible. Marketing efficiency can be of two types; that is operational/technical efficiency which involves the right combination of operations or technologies in the marketing process that will yield the maximum result without altering the quality of the commodity and economic efficiency which is measured in economic terms. For example, what are the best market activities that can be combined to ensure that the commodity reaches the consumer at a relatively fair price that is still profitable to the producer? Marketing efficiency is also summarily put as the input to output ratio in the process of marketing. It can be measured by consumer price, market competition, and marketing margins.

\section{MATERIALS AND METHODS}

\section{A. Study Area}

The study was conducted in the Federal Capital Territory (FCT) with a population of approximately 3,000,000 persons and a landmass of approximately 7,315 $\mathrm{km}^{2}$. There are six (6) Area Councils (ACs)in the country's capital city namely; Abaji, Abuja Municipal Area Council (AMAC), Bwari, Gwagwalada, Kwali and Kuje Area Councils, It is bounded by Kogi, Niger, Nassarawa, Kaduna States all in the NorthCentral Geopolitical Zone of Nigeria. The FCT which falls within the Savannah Zone experiences both rainy and dry seasons between April - October and November - March respectively. It has an average annual temperature of $26.1^{\circ}$, average humidity of about $35 \%$ and average annual rainfall of $1330 \mathrm{~mm}$. This weather favours agricultural activities including the cultivation of yam, rice, maize, cassava, cowpea and other arable crops as well as livestock production.

\section{B. Data Collection and Sampling Procedure}

Respondents in the study area were interviewed using pretested well-structured two sets of questionnaires to obtain primary data. Multistage sampling was used for sampling the respondents such that purposive sampling was used in the first stage. In this stage, three out of e six Area Councils in the FCT were selected on the basis of proximity and concentration of paddy and locally milled rice marketers. These ACs were Kwali, Gwagwalada and Bwari. One major market each was selected purposively from two wards in each of the Area Councils in the second stage. In the third stage, data were randomly collected from 171 paddy rice marketers and 222 locally rice marketers were obtained and analyzed. 


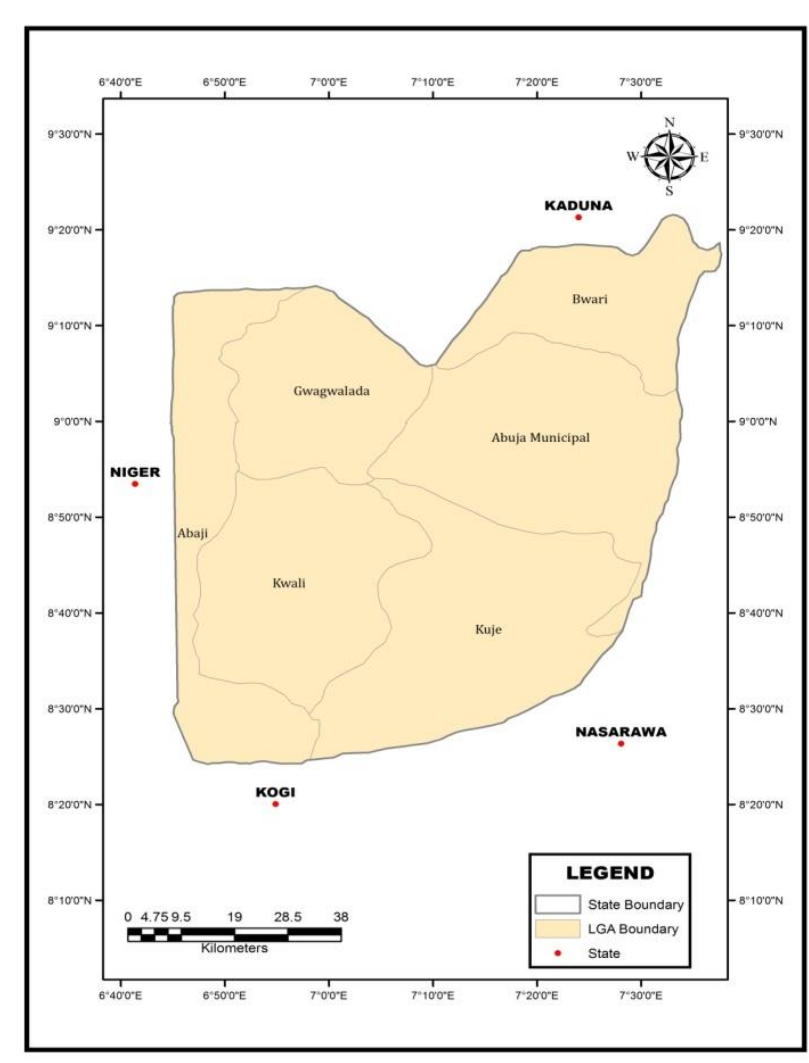

Fig. 1. Map of the Federal Capital Territory (FCT). Source: Google Maps (2019).

\section{Analytical Technique}

The marketing efficiencies of paddy and locally milled rice marketers were determined using Shepherd's Index as follows:

\section{Marketing Efficiency Index $($ paddy/locally milled rice $)=(\mathrm{V} / \mathrm{I})-1$}

where:

$\mathrm{ME}=$ Marketing Efficiency Index of paddy/locally milled rice;

$\mathrm{V}=$ Value of paddy/locally milled rice sold in $\# /$ bag or consumer price;

$\mathrm{I}=$ Total marketing cost of paddy/locally milled rice in $\mathrm{N}$.

Ordinary Least Square multiple regression model was used to identify the factors determining the marketing efficiencies of paddy and locally milled rice as follows:

$Y_{(\text {paddy/locally milled rice })}=\beta_{0}+\beta_{1} X_{1}+\beta_{2} X_{2}+\beta_{3} X_{3}+\beta_{4} X_{4}+\beta_{5} X_{5}$ $+\beta_{6} X_{6}+\beta_{7} X_{7}+\beta_{8} X_{8}+\beta_{9} X_{9}+\beta_{10} X_{10}+\beta_{11} X_{11}+\mu_{i}$

where:

$\mathrm{Y}_{(\text {Paddy hocally milled rice })}=$ Marketing Efficiency Index of paddy/locally milled rice;

$\beta_{0}=$ Constant;

$\beta_{1 \ldots 12}=$ Coefficients of the explanatory variables;

$\mathrm{X}_{1}=$ Age of the respondents in years;

$\mathrm{X}_{2}=$ Sex of marketer $($ Dummy Variable; Male $=1$; Female $=$ $0)$;

$\mathrm{X}_{3}=$ Level of Education (Years of schooling);
$\mathrm{X}_{4}=$ Household Size;

$\mathrm{X}_{5}=$ Marketing experience in years;

$\mathrm{X}_{6}=$ Access to Credit (Dummy Variable; Yes = $;$;o $=0$ );

$\mathrm{X}_{7}=$ Membership of market association (Dummy Variable;

Yes $=1 ;$ No $=0$ )

$\mathrm{X}_{8}=$ Cost of purchasing rice in

$\mathrm{X}_{9}=$ Selling price of rice in

$\mathrm{X}_{10}=$ Distance to market in $\mathrm{Km}$;

$\mathrm{X}_{11}=$ Access to storage facilities (Dummy Variable; Yes = 1;

No $=0$ )

$\mathrm{X}_{12}=$ Existence of contract marketing arrangement (Dummy

Variable; Yes $=1 ;$ No $=0$ );

$\mu_{\mathrm{i}}=$ Error term.

T-test for two independent samples was used to test $\mathrm{Ho}_{1}$ :

$$
t=\frac{\bar{X}_{1}-\bar{X}_{2}}{\sqrt{\frac{S_{1}^{2}}{N_{1}}+\frac{S_{2}^{2}}{N_{2}}}}
$$

where:

$t=\mathrm{T}$-calculated;

$\overline{\mathrm{X}}_{1}-\overline{\mathrm{X}}_{2}=$ the mean difference of paddy and locally milled rice marketers;

$\mathrm{S}_{1}^{2}=$ variance of paddy rice (units);

$\mathrm{S}_{2}{ }^{2}=$ variance of locally milled rice (units);

$\mathrm{n}_{1}=$ number of respondents for paddy rice;

$\mathrm{n}_{2}=$ number of respondents for locally milled rice.

\section{RESULTS AND DisCUSSIONS}

\section{A. Marketing Efficiencies of Paddy and Locally Milled Rice Marketers}

Efficiency is a measure of performance of the processes used in transforming a set of inputs into output and in this case, it involves the cost of marketing relative to the value from marketing. Table I shows the frequency distribution of marketing efficiencies of paddy and locally milled rice in the study area as estimated using the Shepherd index. The table shows that $45.6 \%$ of the paddy rice marketers fell within the efficiency range of $0.81-0.90$, while $40.5 \%$ of the milled rice marketers fell within the efficiency range of $0.71-0.80$. More so, $35.7 \%$ of the paddy rice marketers fell within the efficiency range of $0.71-0.80$ while $29.3 \%$ of the sampled milled rice farmers fell within the efficiencies range of $0.81-$ 0.90 . Results from the analysis also showed that $14 \%$ of the sampled paddy rice marketers fell within the efficiency range of $0.61-0.70$ while $18.9 \%$ of the locally milled rice marketers had an efficiency range within $0.61-0.70$. Again, $2.9 \%$ of the paddy rice marketers had an efficiency range between $0.51-$ 0.60 while $7.2 \%$ of the locally milled rice marketers had an efficiency range between $0.91-1.00$. About $3 \%(3.2 \%)$ of the sampled locally milled rice marketers had an efficiency range between 0.51 and 0.60 while $1.2 \%$ of the sampled paddy rice marketers had an efficiency of not more than $0.50(\leq 0.50)$. About $1 \%(0.9 \%)$ of the sampled locally milled rice marketers had the efficiency of not more than $0.50(\leq 0.50)$ 
while $0.6 \%$ of the sampled paddy rice marketers had the efficiency range of between 0.91-1.00. Results also showed that the mean marketing efficiency of the paddy and the locally milled rice marketers is 0.78 and 0.77 , respectively. This implies that paddy and locally milled rice marketers were $78 \%$ and $77 \%$ efficient in rice marketing, which invariably means they were $22 \%$ and $23 \%$ are inefficient in the marketing of local rice, respectively. The minimum marketing efficiency of the paddy and the locally milled rice marketers is 0.09 and 0.50 respectively while the maximum marketing efficiency is 0.91 and 0.99 respectively. These results agree with the findings of [21] and [22].

TABLE I: MARKETING EFFICIENCIES OF PADDY AND LOCALLY MILLED RICE MARKETERS IN THE FCT

\begin{tabular}{|c|c|c|c|c|}
\hline \multirow{2}{*}{$\begin{array}{c}\text { Marketing } \\
\text { Efficiency } \\
\text { Range }\end{array}$} & \multicolumn{2}{|c|}{ Paddy Rice } & \multicolumn{2}{|c|}{ Locally Milled Rice } \\
\hline & Frequency & Percentage & Frequency & Percentage \\
\hline$\leq 0.50$ & 2 & 1.2 & 2 & 0.9 \\
\hline $0.51-0.60$ & 5 & 2.9 & 7 & 3.2 \\
\hline $0.61-0.70$ & 24 & 14.0 & 42 & 18.9 \\
\hline $0.71-0.80$ & 61 & 35.7 & 90 & 40.5 \\
\hline $0.81-0.90$ & 78 & 45.6 & 65 & 29.3 \\
\hline $0.91-1.00$ & 1 & 0.6 & 16 & 7.2 \\
\hline Total & 171 & 100.0 & 222 & 100.0 \\
\hline Mean & \multicolumn{2}{|c|}{0.78} & \multicolumn{2}{|c|}{0.77} \\
\hline Minimum & \multicolumn{2}{|c|}{0.09} & \multicolumn{2}{|c|}{0.50} \\
\hline Maximum & \multicolumn{2}{|c|}{0.91} & \multicolumn{2}{|c|}{0.99} \\
\hline
\end{tabular}

Source: Computed from field data, 2019.

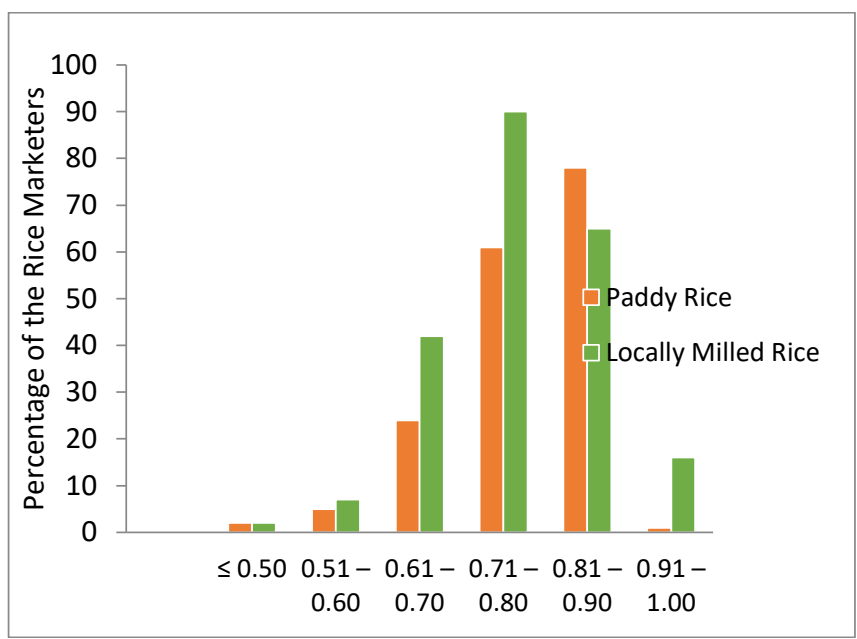

Fig. 2. Frequency Distribution of Paddy and Locally Milled Rice Marketers by their Marketing Efficiencies in the FCT.

\section{B. Factors Determining Marketing Efficiencies of Paddy and Locally Milled Rice in the FCT}

The data collected was fitted into a multiple regression model using ordinary least square (OLS) as an estimator. The diagnostic statistics showed that the F-statistic were significant at $1 \%$ level of significance for both the paddy and the locally milled rice marketers, implying that the correlation between the regression model and independent variables is statistically significant. The $\mathrm{R}^{2}$ were 0.629 and 0.859 for paddy and locally milled rice marketers respectively, showing the goodness of fit of the regression (i.e., the explanatory powers of the specified variables). This implied that $62.9 \%$ and $84.8 \%$ of the variation in marketing efficiency for both paddy and locally milled rice respectively were explained by the independent variables embedded in the model. The factors considered were sex, level of education, household size, marketing experience, credit access, membership of marketing association, cost of purchasing the commodity, the selling price of the commodity, distance to the nearest market, access to storage, and marketing contract arrangement

\section{1) $\operatorname{Sex}$}

Sex of the respondents was measured as a dummy, with any male respondent dummied as 1 and female dummied 0 . Sex of the respondents had a positive and statistically significant relationship with the marketing efficiency of paddy rice marketers at $5 \%$ level of significance. In line with a priori expectation, the result showed that male paddy rice marketers were more efficient than their female counterparts. This implied that a unit increase in the number of male paddy respondents would increase the marketing efficiency of the paddy rice marketers by 5.49 .

\section{2) Level of Education}

There is a statistically significant negative relationship between the level of education and the marketing efficiencies of paddy rice and locally milled rice marketers. This implied that marketing efficiency increases with a decrease in the number of years spent in school and is a deviation from $a$ priori expectation. The result is hinged on the fact that an increase in the cost of education as more years are spent in school decreases disposable income and time required for marketing.

\section{3) Household size}

There is a positive relationship between household size and the marketing efficiency of paddy rice and a negative relationship with the marketing efficiency of locally milled rice. This implies that marketing efficiency increases with an increase in the household size of paddy rice marketers and decreases with an increase in the household size of locally milled rice marketers in the study area. Marketing performance of the respondents increased with an increase in persons available to assist with marketing within a household. This is in line with the findings of [23]. On the other hand, a unit increase in household size would decrease the marketing efficiency of locally milled rice by $0.0019(0.19 \%)$, implying that a large household size may not be required to improve the marketing performance of the respondents. The result for locally milled rice marketers agrees with the findings of [22] [24] [25].

\section{4) Membership of association}

Membership of association had a positive and statistically significant relationship with the marketing efficiency of locally milled rice marketers at $1 \%$ level of significance. This implied that membership of a marketing association had a positive influence on marketing efficiency. A unit increase in membership of the marketing association would increase the marketing efficiency of locally milled rice by 0.645 . This is considering that membership of marketing association is beneficial to locally milled rice marketers and is not farfetched from the fact that support from governments cannot be accessed by an individual marketer except through cooperatives and/or associations. Their membership increased their bargaining power for better factor and product prices as well as increased their access to market information 
while increasing their economies of scale because inputs are available at cheaper rates; commodities are transported collectively to save costs while access to markets is ensured by this associations thus increasing the marketers' profit margin in comparison with persons who bear individual costs and may not be able to access necessary market inputs and information. This agrees with the findings of [26] and [19].

\section{5) Marketing experience of the respondents}

There is a positive and statistically significant relationship between marketing experience and marketing efficiency of locally milled rice. That is a unit increase in the years of marketing experience translates to an increase in marketing efficiency by $0.0002(0.02 \%)$ This implied that locally milled rice marketers with more years of experience are found to be market efficient than those with few years of experience in rice marketing. This is in line with the a priori expectation and corroborates the findings of [23].

\section{6) Cost of Purchasing Rice}

The cost of purchasing paddy rice had a positive statistically significant relationship with marketing efficiency in the study area. That is, a unit increase in the cost price of paddy rice increased marketing efficiency by 28.61 . This is a deviation from a priori expectation considering that a higher cost price is expected to translate to increased selling price in order to increase profit margin, and higher selling price would discourage consumers and decrease demand. This result is in line with the findings of [15].

\section{7) Selling Price of Rice}

The selling price of rice had a statistically significant negative relationship with marketing efficiency of locally milled rice. This is further explained; thus, the result showed that a unit increase in the selling price of locally milled rice that is, price to be paid by consumers, would lead to a decrease in marketing efficiency by 0.0001 . The result is not farfetched considering that higher selling price discourages consumers from purchasing the commodity hence, the likelihood of having a negative impact on marketing performance viz-a-viz marketing efficiency.

\section{8) Distance to/from the nearest market}

Distance is negatively related to the marketing efficiency of locally milled rice. This means a unit increase in the distance to the nearest market would lead to 0.00045 decrease in marketing efficiency of locally milled rice marketers in the area, implying that long distance (i.e., remoteness of the marketers' residences to the market) reduces marketing efficiency of rice marketers in the study area. This is no surprise and is in line with the a priori expectation, as long distance often translates to increased marketing cost in the form of cost of transportation.

\section{9) Availability of Storage Facility}

Availability of storage facility had a statistically significant positive and negative relationship with marketing efficiencies of paddy and locally milled rice respectively. That is, marketing efficiency of paddy rice increases with the availability of storage facilities. This is not far-fetched as it is believed that paddy purchased and stored in November has a higher profit margin than locally milled rice when sold in June/July of the following year. It is also worthy of note that availability of storage facilities reduces wastages and ensures that marketers are able to sell the commodity during harvest and off seasons. On the contrary, marketing efficiency of locally milled rice decreases with the availability of storage facility. This is in line with economic theory, considering that increased cost of storage translates to increased marketing costs which decreases efficiency.

\section{0) Contract marketing arrangement}

Contract marketing arrangement is a marketing arrangement that gives assurance to the marketers. The variable has a positive and statistically significant relationship with marketing efficiencies of paddy rice marketers and locally milled rice marketers. This means that an increase in the contract marketing arrangement would increase marketing efficiencies of paddy rice marketers and the locally milled rice marketers. This is in line with a priori expectations. The gains that lie in contract marketing arrangement which include that the grade and price of the commodity are known well ahead of time, gives the marketer an edge over persons who do not have this information. In addition, in some cases, the other partner in the contract bears the costs of packaging and transportation.

TABLE II A: Parameter Estimates of the FACtors Determining Marketing EFFiciencies of PAdDy Rice Marketers in the FCT

\begin{tabular}{cccc}
\hline \hline Variable & Coefficient & Standard Error & t-value \\
\hline Constant & 25.2297 & 3.2131 & 7.85 \\
Sex (Dummy, 1 if male, 0 otherwise) & 5.4903 & 2.6851 & $2.04^{* *}$ \\
Education (Years of Schooling) & -0.1488 & 0.0754 & $-1.97^{* *}$ \\
Household Size (Number) & 0.7368 & 0.1273 & $5.79^{* * *}$ \\
Marketing Experience (years) & 0.3499 & 0.0635 & $5.51^{* * *}$ \\
Access to Credit (Dummy, 1 if yes, 0 otherwise) & 0.00002 & 0.00002 & 1.04 \\
Membership of Marketing Association & -0.2081 & 1.3628 & -0.15 \\
Cost of Purchasing Rice (In Naira) & 0.0001 & 0.0001 & 0.70 \\
Selling Price of Rice (In Naira) & -0.0001 & 0.0001 & -0.70 \\
Distance & -0.1239 & 0.0838 & -1.48 \\
Access to Storage Facilities (Dummy, 1 if yes, 0 & 3.8806 & 1.3148 & $2.95^{* * *}$ \\
$\quad$ otherwise) & & & $1.99^{* *}$ \\
Contract Arrangement (Dummy, 1 if yes, 0 & 2.8836 & 1.4512 & \\
otherwise) & & & \\
Diagnostic Statistics: & 171 & & \\
Number of Observations & & \\
R-squared & 0.6290 & & \\
F-Statistics (11, 157) & $24.19^{* * *}$ & & \\
\hline \hline
\end{tabular}

$* * *, * *$, and $*$ means level of significance at $1 \%, 5 \%$ and $10 \%$ respectively.

Source: Computed from field data, 2019. 
TABLE IIB: PARAMETER ESTIMATES OF THE FACTORS DETERMINING MARKETING EFFICIENCIES OF LOCALLY MILLED RICE MARKETERS IN THE FCT

\begin{tabular}{cccc}
\hline Variable & Coefficient & Standard Error & $\mathrm{t}$-value \\
Constant & 0.8102 & 0.0189 & 42.74 \\
Age (years) & -0.0005 & 0.0004 & -1.47 \\
Sex (Dummy, 1 if male, 0 otherwise) & -0.0026 & 0.0117 & -0.23 \\
Education (Years of Schooling) & -0.0012 & 0.0004 & $-2.77^{* * *}$ \\
Household Size (Number) & -0.0019 & 0.0010 & $-1.86^{*}$ \\
Marketing Experience (years) & 0.0002 & 0.0005 & 0.33 \\
Membership of Marketing Association (Dummy, 1 if yes, 0 otherwise) & 0.0250 & 0.0078 & $3.19^{* * *}$ \\
Cost of Purchasing Rice (In Naira) & 0.0001 & 0.000003 & $28.61^{* * *}$ \\
Selling Price of Rice (In Naira) & -0.0001 & 0.0000002 & $-25.43^{* * *}$ \\
Distance (In Km) & -0.0005 & 0.0002 & $-2.95^{* * *}$ \\
Access to Storage Facilities (Dummy, 1 if yes, 0 otherwise) & -0.0224 & 0.0073 & $-3.08^{* * *}$ \\
Contract Arrangement (Dummy, 1 if yes, 0 otherwise) & -0.0256 & 0.0116 & $2.21^{* *}$ \\
\hline Diagnostic Statistics: & & & \\
Number of Observations & 222 & &
\end{tabular}

$* * *, * *$, and $*$ means level of significance at $1 \%, 5 \%$ and $10 \%$ respectively.

Source: Computed from field data, 2019.

\section{Test of Hypotheses}

The null hypothesis $\mathrm{Ho}_{1}$ that stressed that there is no significant difference between the marketing efficiencies of paddy and locally milled rice in the study area is accepted because the result of the t-test of two independent samples showed a t-value of 0.381 .

TABLE III: T-TEST OF THE MARKETING EFFICIENCIES OF PADDY AND LOCALLY MILLED RICE MARKETERS IN THE FCT

\begin{tabular}{|c|c|c|c|c|c|c|}
\hline & \multicolumn{2}{|c|}{$\begin{array}{c}\text { Levene's Test } \\
\text { for Equality of } \\
\text { Variances }\end{array}$} & \multicolumn{3}{|c|}{$\begin{array}{l}\text { t-test for Equality of } \\
\text { Means }\end{array}$} & \multirow{2}{*}{$\begin{array}{c}\text { Remarks } \\
\text { Sig./Not } \\
\text { Sig. }\end{array}$} \\
\hline & $\begin{array}{c}\text { F- } \\
\text { value }\end{array}$ & Sig. & $\begin{array}{c}\mathrm{t}- \\
\text { value }\end{array}$ & Df & $\begin{array}{c}\text { Sig. } \\
(2- \\
\text { tailed) } \\
\end{array}$ & \\
\hline $\begin{array}{c}\text { Equal } \\
\text { variances } \\
\text { assumed } \\
\text { Equal }\end{array}$ & 0.272 & 0.603 & 0.381 & 391 & 0.704 & $\begin{array}{c}\text { Not } \\
\text { Significant }\end{array}$ \\
\hline $\begin{array}{c}\text { variances } \\
\text { not } \\
\text { assumed }\end{array}$ & & & 0.381 & 334.615 & 0.709 & $\begin{array}{c}\text { Not } \\
\text { Significant }\end{array}$ \\
\hline
\end{tabular}

\section{CONCLUSION}

The study concludes that marketing of paddy and locally milled rice were found to be efficient in the Federal Capital Territory, and that there is no significant difference between the marketing efficiencies of both commodities. Also, contract arrangement greatly improves marketing efficiencies of both paddy and locally milled rice marketers. The study therefore recommends the need for government to formulate policies in favour of local rice marketing; intensify infrastructural development especially the construction of rural roads to reduce the cost of transporting goods and facilitate youth and women inclusiveness in marketing local rice. Private investors are also encouraged to facilitate contract marketing arrangements as this was discovered to play a significant role in improving marketing efficiency.

\section{REFERENCES}

[1] Food and Agriculture Organisation of the United Nations, "Bridging the Rice Yield Gap in the Asia - Pacific Region", A report submitted at an Expert Consultation, 2016.
[2] V. Deepak, "Nutritional Value of Rice and Their Importance". Indian Farmer's Digest, pp. 44. 21, 2011.

[3] P. R. Chaudhari, N. Tamrakar, L. Singh, A. Tandon, D. Sharma, "Rice Nutritional and Medicinal Properties: A Review Article", Journal of Pharmacognosy and Phytochemistry, Vol. 7(2), pp. 150 - 156, 2018.

[4] U. Ahuja, S. C. Ahuja, R. Thakrar, R. K. Singh, "Rice a Nutraceutical", Asian-Agri History, Vol. 12 (2), pp. 93 - 108, 2008.

[5] PriceWaterHouse Coopers, "Boosting Rice Production in Nigeria through Mechanization", A report published by Pwc, 2017.

[6] A. S. Ajala, A. Gana, "Analysis of Challenges Facing Rice Processing in Nigeria", Journal of Food Processing, Vol. 2015, Article ID 893673, pp. 6, 2015.

[7] S. O. Oikeh, F. E. Nwilene, T. A. Agunbiade, O. Oladimeji, O. Ajayi, S. Mande, H. Tsunematsu, H. Samejima, "Growing Upland Rice: A Production Handbook", Africa Rice Center: Cotonou, Benin, pp. 3. 2008.

[8] B. U. Ugalahi, S. O. Adeoye, M. U. Agbonlahor, "Irrigation Potentials and Rice Self-Sufficiency in Nigeria: Review", African Journal of Agricultural Research, Vol. 11 (5), pp. 298-309, 2016.

[9] D. A. Abah, G. A. Anjeinu, P. A. Iorhon, "Analysis of Performance of Paddy Marketing in Benue State, Nigeria”, Journal of Agricultural Science and Engineering, Vol. 1 (3), pp. 143-152, 2015.

[10] I. M. S. Inuwa, U. B. Kyiogwom, A. L. Ala, M. A. Maikasuwa, N. D. Ibrahim, "Profitability Analysis of Rice Processing and Marketing in Benue State, Nigeria", Nigerian Journal of Basic and Applied Science, Vol. 19 (2), pp. 293-298, 2011.

[11] USAID, "Global Food Security Response: West African Rice ValueChain Analysis", Global Food Security Response: Nigeria Rice Study, 2013. Available on http://www.marketlinks.byf1.io/library/globalfood-security-response-west-africa-rice-value-chain-analysis.

[12] The Guardian Newspaper, "Nigeria: Porous Borders, Unending Rice Smuggling Weighs on Local Production", A news report on May $29^{\text {th }}$, 2019. Available on https://allafrica.com/stories/201905290464.html.

[13] E. Ugwu, A. Adepetun, "Food Prices Crashes': Nigeria Braces Up", The Guardian, 27, 2008.

[14] N. Emeka, J. N. Ugwu, "Economic Viability of Processing and Marketing of Rice in Uzouwani Local Government Area of Enugu State, Nigeria", Developing Country Studies, Vol. 5 (17), pp. 111-114, 2015.

[15] I. O. Oyewo, E. O. Oladipupo-Alade, O. O. Oke, A. A. Ademuwagun, R. T. Alabi, "Economic Analysis of Rice Marketing in Ibadan North Local Government Area, Oyo State - Nigeria", Conference Proceedings of the $18^{\text {th }}$ Annual National Conference of the Nigeria Association of Agricultural Economists held 16 $6^{\text {th }}-19^{\text {th }}$ October, 2017.

[16] Y. Dauna, D. Y. Giroh, W. B. Adamu, "Analysis of the structure and Performance of paddy rice marketing in Adamawa State, Nigeria", Agricultural Science and Technology, Vol. 10 (2), pp. 174-177, 2018.

[17] A. Takele, "Analysis of Rice Profitability and Marketing Chain: The Case of Fogera Wodera, South Gondar Zone, Amhara Regional State, Ethiopia", An Msc Thesis submitted to the College of Agricultural Economics, Haramaya University, Ethiopia, 2010.

[18] J. O. Nwele, "Economics of Rice Production and Marketing in Nigeria: A Study of Ebonyi State", International Journal for Research in Business, Management and Accounting Vol. 2(5), pp. 17-37, 2016.

[19] A. O. Ejoha, "Economics of Paddy Rice Marketing in Nasarawa State, Nigeria", An Unpublished M. Sc Dissertation submitted to the Department of Agricultural Economics, University of Abuja, Nigeria, 2019. 
[20] C. N. Anthony, M. Anyalor, "Marketing Analysis of Locally Produce Rice in Abakaliki Local Government Area of Ebonyi State, Nigeria", Mediterranean Journal of Social Sciences, Vol. 10 (1), pp. 39-47, 2019.

[21] B. Najafi, M. Zibahi, "Survery on Technical efficiency of wheat farmers in Fars Province", Iranian Journal of Agricultural Economics and Development, Vol. 3 (7), pp. 71-81, 1995.

[22] M. Obwona, "Determinants of Technical Efficiency Differentials amongst Small-and Medium-Scale Farmers in Uganda: A Case of Tobacco Growers", A final report presented at AERC Bi-annual workshop, Nairobi, Kenya, 2000

[23] D. T. Tondo, A. C. Iheanach, "The Relationship Between Socioeconomic Characteristics of Rice-Marketing Actors and Value Addition in Rice in Benue State", International Journal of Scholarly Research, Vol. 1(1), pp. 50-60, 2015.

[24] H. Mulie, "The Determinants of Profit Efficiency of Coffee Producing and Marketing Cooperatives (The case study of Sidama Coffee farmers' Union)", Journal of Economics and Sustainable Development, Vol. 5(11), pp. 108-120, 2014.

[25] M. Obwona, "Determinants of Technical Efficiency Differentials amongst Small-and Medium-scale Farmer in Uganda: A case of Tobacco Grower", African Economic Research Consortium (AERC) Research Paper 152, Nairobi, Kenya, 2006.

[26] A.A.A. Coker, F.D. Ibrahim, U.N. Ibeziako, "Effects of Household Demographics on the Technical Efficiency of Cowpea Farmers: Evidence of Stochastic Function Analysis in Nigeria", Russian Journal of Agricultural and Socio-Economic Sciences, Vol. 1(173), pp. 179$186,2018$. 